\title{
Impact of HIV and AIDS on food security in Rufiji District, Tanzania
}

\author{
Author: \\ Kim A. Kayunze ${ }^{1}$ \\ Affiliation: \\ ${ }^{1}$ Development Studies \\ Institute, Sokoine University \\ of Agriculture, Tanzania \\ Correspondence to: \\ Kim Kayunze \\ Email: \\ kim.kayunze@sacids.org \\ Postal address: \\ PO Box 3024, Morogoro, \\ Tanzania \\ How to cite this poster: \\ Kayunze, K.A., 2012, 'Impact \\ of HIV and AIDS on food \\ security in Rufiji District, \\ Tanzania', Onderstepoort \\ Journal of Veterinary \\ Research 79(2), Art. \#482, \\ 1 page. http://dx.doi. \\ org/10.4102/ojvr.v79i2.482 \\ Note: \\ Proceedings of the \\ Conference of the Southern \\ African Centre for Infectious \\ Disease Surveillance 'One \\ Health' held at the National \\ Institute for Communicable \\ Diseases, Johannesburg, July \\ 2011.
}

Relatively high prevalence of HIV and AIDS and food insecurity in Rufiji District whilst the linkage between the two problems was not known was the basis of this study. Data were collected amongst 225 households between November 2005 and October 2006 through participatory rural appraisal (PRA), household income and expenditure survey (HIES) and structured interviews. Binary logistic regression was used for analysis in which case the dependent variable was food security in terms of food insecure (0) and food secure (1) based on kilocalories consumed per adult equivalent per day. The independent variables included having been affected by HIV and AIDS in terms of not affected (0) and affected (1). The results reveal that the odds for households affected by HIV and AIDS to be food secure were 0.705 times as high as the odds for households not affected by HIV and AIDS to be food secure. This means that households affected by HIV and AIDS were less likely to be food secure as opposed to those not affected by HIV and AIDS. The B statistic for having been affected by HIV and AIDS was negative $(B=-0.350)$ meaning that being affected by HIV and AIDS had negative impact on food security. However, the Wald statistic which shows the magnitude of impact was small $(0.251)$ and not significant $(p=0.617)$. This shows that HIV and AIDS had little impact on food security. Based on these findings, it is concluded that although being affected by HIV and AIDS has negative impact on food security, it does not automatically make households food insecure, especially in a short run, and that some non-HIV and AIDS factors like high dependency ratio and low ability to buy food have bigger negative impact than that of HIV and AIDS on food security. On the basis of the conclusion, it is recommended that efforts to improve food security amongst households affected by HIV and AIDS should consider both HIV and AIDS and non-HIV and AIDS factors.
C 2012. The Authors. Licensee: AOSIS OpenJournals. This work is licensed under the Creative Commons Attribution License. 